\title{
BMJ Open Ecological study on the use of hormonal contraception, abortions and births among teenagers in the Nordic countries
}

\author{
Helena Hognert, ${ }^{1}$ Finn Egil Skjeldestad, ${ }^{2}$ Kristina Gemzell-Danielsson, ${ }^{3}$ \\ Oskari Heikinheimo, ${ }^{4}$ Ian Milsom, ${ }^{1}$ Øjvind Lidegaard, ${ }^{5}$ Ingela Lindh ${ }^{1}$
}

To cite: Hognert $\mathrm{H}$, Skjeldestad FE, GemzellDanielsson $\mathrm{K}$, et al. Ecological study on the use of hormonal contraception, abortions and births among teenagers in the Nordic countries. BMJ Open 2018;8:e022473. doi:10.1136/ bmjopen-2018-022473

- Prepublication history for this paper is available online. To view these files, please visit the journal online (http://dx.doi. org/10.1136/bmjopen-2018022473).

Received 25 February 2018

Revised 10 July 2018

Accepted 14 September 2018

Check for updates

(c) Author(s) (or their employer(s)) 2018. Re-use permitted under CC BY-NC. No commercial re-use. See rights and permissions. Published by BMJ.

For numbered affiliations see end of article.

Correspondence to

Dr Ingela Lindh;

ingela.lindh@vgregion.se

\section{ABSTRACT}

Objectives Compare hormonal contraceptive use, birth and abortion rates among teenagers in the Nordic countries. A secondary aim was to explore plausible explanations for possible differences between countries. Design Ecological study using national registry data concerning births and abortions among all women aged 15-19 years residing in Denmark, Finland, Iceland, Norway and Sweden 2008-2015. Age-specific data on prescriptions for hormonal contraceptives for the period 2008-2015 were obtained from national databases in Denmark, Norway and Sweden.

Setting Denmark, Finland, Iceland, Norway and Sweden. Participants Women 15-19 years old in all Nordic countries (749 709) and 13-19 years old in Denmark, Norway and Sweden (815 044).

Results Both annual birth rates and abortion rates fell in all the Nordic countries during the study period. The highest user rate of hormonal contraceptives among 15-19-year-olds was observed in Denmark (from $51 \%$ to $47 \%$ ) followed by Sweden (from 39\% to $42 \%$ ) and Norway (from $37 \%$ to $41 \%$ ). Combined oral contraceptives were the most commonly used methods in all countries. The use of long-acting reversible contraceptives (LARC), implants and the levonorgestrel-releasing intrauterine systems, were increasing, especially in Sweden and Norway. In the subgroup of 18-19-year-old teenagers, the user rates of hormonal contraceptives varied between $63 \%$ and $61 \%$ in Denmark, $56 \%$ and $61 \%$ in Norway and $54 \%$ and $56 \%$ in Sweden. In the same subgroup, the steepest increase of LARC was seen, from $2 \%$ to $6 \%$ in Denmark, $2 \%$ to $9 \%$ in Norway and $7 \%$ to $17 \%$ in Sweden.

Conclusions Birth and abortion rates continuously declined in the Nordic countries among teenagers. There was a high user rate of hormonal contraceptives, with an increase in the use of LARC especially among the oldest teenagers.

\section{INTRODUCTION}

Teenage pregnancy is regarded as a challenge both to society and the teenager. ${ }^{1}$ Adolescent pregnancy and motherhood is associated with low socioeconomic status, early school leaving and poor health of the mother during and after pregnancy. ${ }^{2-6}$ Also, the child of a teenage mother is at risk both during the perinatal

\section{Strengths and limitations of this study}

- The main strength of this study was the use of national register data, including all adolescents in the Nordic countries.

- In this study, data on redeemed prescriptions have been used since it has been shown to be more reliable than self-reported use of contraceptives.

- Non-hormonal contraceptives are not registered in any of the national databases and hence were not included in this study.

- Since personal identification data are not recorded for contraceptive sales in Finland and Iceland, use of hormonal contraceptives were only available from Denmark, Norway and Sweden.

period and in the long-term. ${ }^{2}$ Socioeconomic deprivation is considered to be both an effect of and a risk factor for teenage births. Hence, ill health and low socioeconomic status are often disseminated across generations. ${ }^{6} 7$ Women experiencing teenage motherhood or teenage abortion are also at risk of having another unplanned pregnancy. ${ }^{8-10}$

In the USA and Europe, the rates of teenage pregnancies are declining, ${ }^{11}$ but there is a large variation both between the USA and Europe and within the European continent. ${ }^{12}$ The outcome of pregnancies differs greatly, where in some regions, most of the teenage pregnancies end with an induced abortion, while in others, a pregnancy is usually continued to term. Although the USA has witnessed a steadily declining teenage pregnancy rate $(57 / 1000$ in 2011$)$, it is still comparable to the highest rates seen in the east-European countries. For example, an incidence of $60 / 1000$ of adolescent pregnancy has recently been reported from Romania and Bulgaria. ${ }^{12}$ In Northern Europe, pregnancy rates vary between high levels of pregnancies and births in England and Wales (47/1000 in 2011) and much lower overall pregnancy rates in the Nordic countries and Ireland. ${ }^{12-14}$ 
The declining rate of teenage pregnancy in the Nordic countries has been documented in several studies. ${ }^{15-17}$ It has been suggested that an increasing availability of contraceptives is one of the reasons for the decline. Patterns of contraceptive use among teenagers have been described in individual Nordic countries ${ }^{161819}$ and as part of European surveys. ${ }^{20}{ }^{21}$ However, recent and comprehensive studies, including data on both pregnancies and contraceptive use among all Nordic teenagers, are lacking.

The aim of this study was to compare hormonal contraceptive use, birth and abortion rates among teenagers in the Nordic countries. A secondary aim was to explore plausible explanations for possible differences between countries.

\section{MATERIAL AND METHODS}

National data on abortion and birth rates among teenagers were compiled from the five Nordic countries, Denmark, Finland, Iceland, Norway and Sweden, from 2000 to 2015.

Data regarding the use of hormonal contraceptives for the period 2008-2015 were only available from Denmark, Norway and Sweden as personal identification data are not recorded for contraceptive sales in Finland and Iceland.

Information on birth and abortion rates were collected from the National Health Registries ${ }^{22}$ and the Tigrab Database $^{23}$ in Denmark, The National Institute for Health and Welfare in Finland, ${ }^{24}$ the Directorate of Health in Iceland,$^{25}$ the Norwegian Institute of Public Health ${ }^{26}$ and the National Board of Health and Welfare in Sweden. ${ }^{27}$ Birth and abortion rates were expressed as the number of births or abortions / 1000 women and year in a certain age group according to international practice. When displaying the overall teenage birth and abortion rates, all births or abortions during 1 year among women $\leq 19$ years of age were included. Even though there is a small number of births and abortions among women younger than 15 years of age, the age group 15-19 was still used as a denominator in accordance with international practice. $^{28}$ Age was further categorised into three groups (13-14, 15-17 and 18-19 years).

In Sweden, the collection of abortion data were temporarily stopped in 2013. When collection started again in 2014, only data for 5-year intervals of age were available; thus, Sweden was not able to provide data for the subgroups of 13-14, 15-17 and 18-19-year-olds from 2013 and onwards.

National data on redeemed prescriptions of hormonal contraceptives in the Nordic countries were collected from the Danish National Registry of Medicinal Product Statistics, ${ }^{29}$ the Norwegian Prescription Database ${ }^{30}$ and the National Board of Health and Welfare in Sweden. ${ }^{27}$ The collected data provide information on sold packages or items of different types of contraceptives expressed as defined daily doses (DDD). Use of combined oral contraceptives (COC), progestogen-only pills (POP), the contraceptive patch, the vaginal ring and the injection were expressed as DDD per 100 women-years (\%). To be able to compare the levonorgestrel-releasing intrauterine system (LNG-IUS) with the other contraceptive methods, the mean duration of use for the two LNG-IUSs available during the study period were set to $4^{31}$ and 2 years, respectively. ${ }^{32}$ Similarly, we calculated duration of use for the etonogestrel implant to be 2 years according to the average duration of use reported in previous studies. ${ }^{31} 33$ All prescribed hormonal contraceptives to women $\leq 19$ years of age were included when user rates among 15-19-year-olds were estimated, although a small number of prescriptions were for women below 15 years of age. As for abortion and birth rates, we also estimated hormonal contraceptive user rates for the age groups 13-14, 15-17 and $18-19$ years.

Use of copper intrauterine device (IUD), condoms, diaphragms and fertility awareness methods was not estimated since these methods are not registered in any national databases. Since personal identification data are not recorded for hormonal emergency contraceptives, these methods are not included either.

Since all variables were collected on a group level from anonymised data including all teenagers, also teenagers who were infertile, not heterosexually active, pregnant or wished to get pregnant were part of the study population.

Demographic data for the Nordic countries were obtained from the database Facts about the Nordic region. ${ }^{34}$

\section{Ethical considerations}

All data included in the study was either already in the public domain or anonymised on receipt.

The legal aspects of utilisation of registry data for study purposes in Denmark and Norway were performed in accordance with national legislation. For Norway, the board of the Norwegian Prescription Database reviewed the protocol and gave permission for use of the data. Studies using anonymous data from nationwide registers are by Norwegian legislation exempted from the need of institutional regulatory board approvals and written informed consent from the patients. The specific permissions from the relevant body were in Denmark achieved from Datatilsynet (journal no 2010-41-4778).

In Finland, Iceland and Sweden, no permission was required as these data are publicly available from the national bodies of these countries. Since patients were not directly involved in the study and only anonymised data were used, no ethical consent was needed.

\section{Patient and public involvement}

There was no direct involvement in the study by patients, since only aggregated and anonymised data were used.

\section{Statistical methods}

In these purely descriptive analyses, no CIs were calculated for the country-specific rates. Since all female 
A

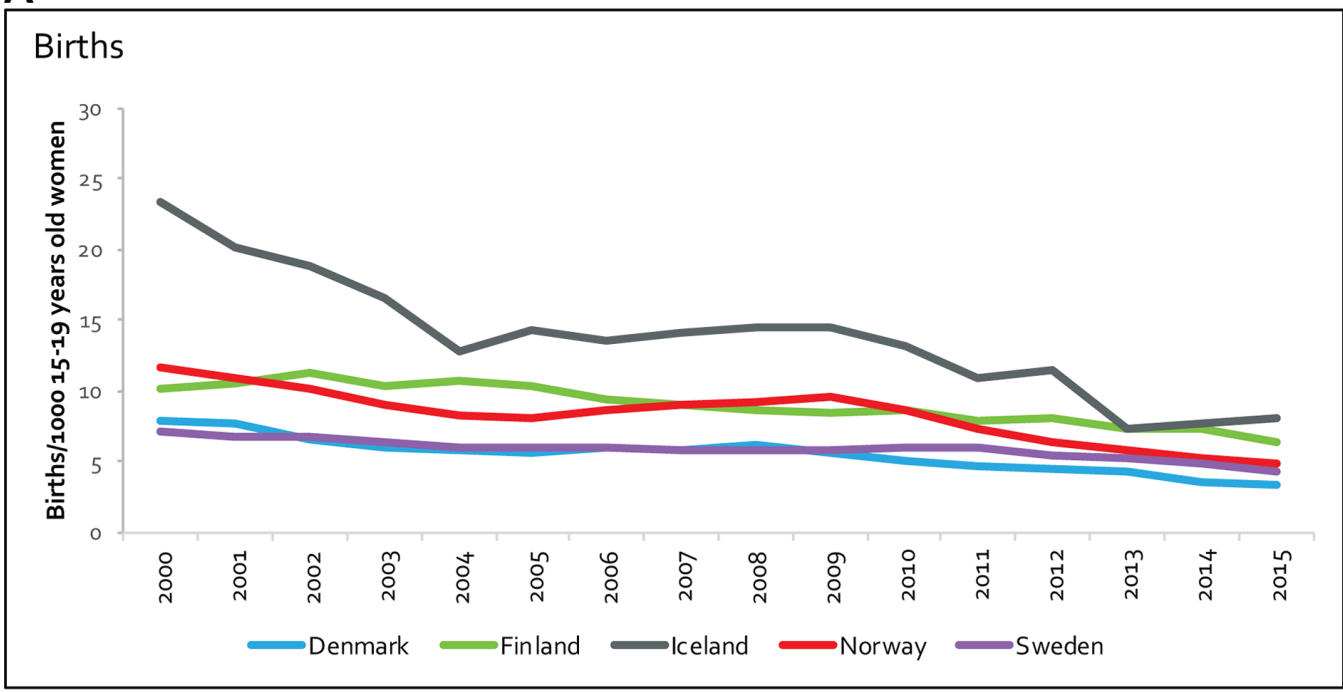

B

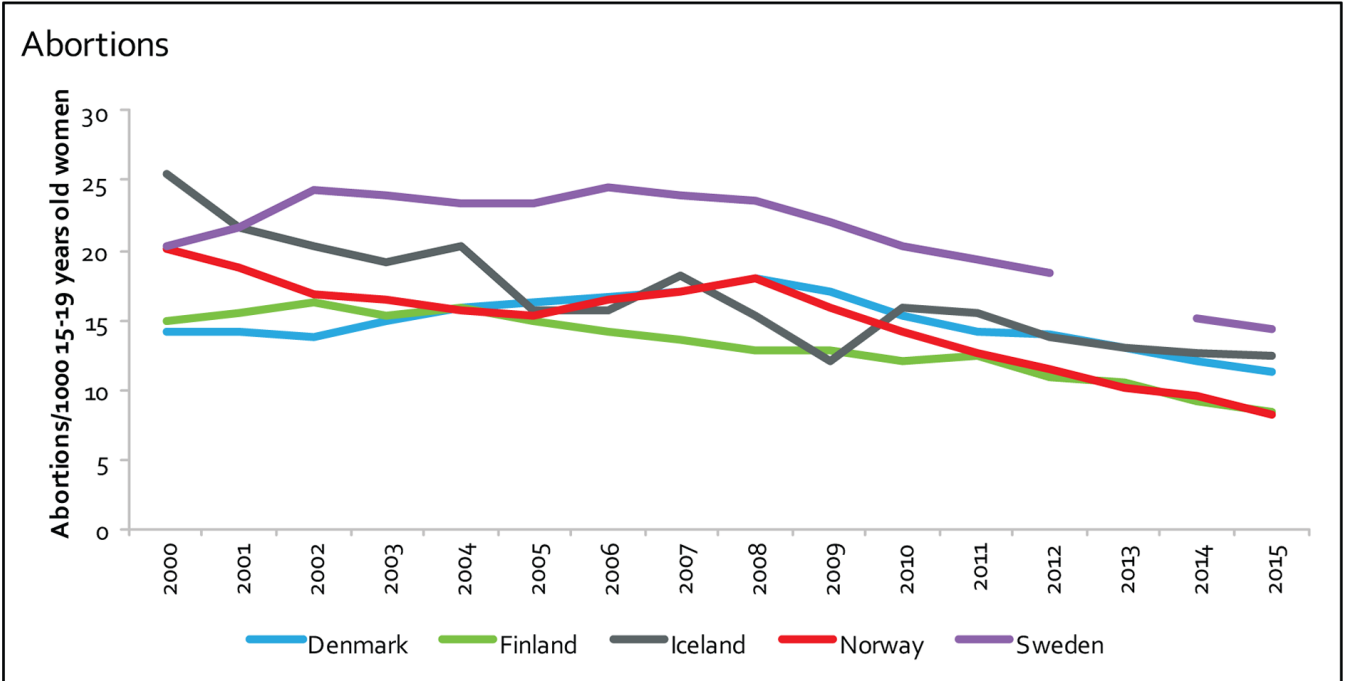

Figure 1 (A) Births/1000 women aged 15-19 during 2000-2015 in the Nordic countries. (B) Abortions/1000 women aged 1519 during 2000-2015 in the Nordic countries. Age-stratified abortion rates were not available for 2013 in Sweden.

teenagers in each specific age group were included, even small differences were highly significant.

\section{RESULTS}

\section{Population}

In 2015, the overall study population comprised 749 709 women 15-19 years old in the Nordic countries. When restricting the analysis to 13-19 years old women in Denmark, Norway and Sweden, the study population comprised 815044 teenagers (2015).

\section{Births, abortions and use of hormonal contraception among teenagers $15-19$ years}

The birth rates fell from 8 to $3 / 1000$ women $15-19$ years in Denmark, 10 to 6 in Finland, 23 to 8 in Iceland, 12 to 5 in Norway and 7 to 4 in Sweden from 2000 through 2015 (figure 1A).

The abortion rates fell from 14 to $11 / 1000$ in women aged 15-19 years in Denmark, 15 to 8 in Finland, 25 to 13 in Iceland, 20 to 8 in Norway and 20 to 14 per 1000 teenagers in Sweden (figure 1B). Both birth and abortion rates decreased which resulted in an overall decline of teenage pregnancy rates in all countries.

The overall use of hormonal contraceptives varied between $51 \%$ and $47 \%$ in Denmark, $37 \%$ and $41 \%$ in Norway and $39 \%$ and $42 \%$ in Sweden from 2008 through 2015 (figure 2A). COC was the most commonly used contraceptive method in all countries, but more frequently used among Danish teenagers, while POP were more common in Sweden ( $7 \%$ to 5\%) and Norway (3\% to $4 \%$ ). The use of long-acting reversible contraceptives (LARC), including implants and the LNG-IUS, increased from $2 \%$ to $4 \%$ in Denmark, $1 \%$ to $7 \%$ in Norway and $5 \%$ to $12 \%$ in Sweden. In Sweden and Denmark, the increase of LARC consisted mainly of a higher use of LNG-IUS, while in Norway the increase of LARC was mainly due to a higher use of implants (figure 2B). 


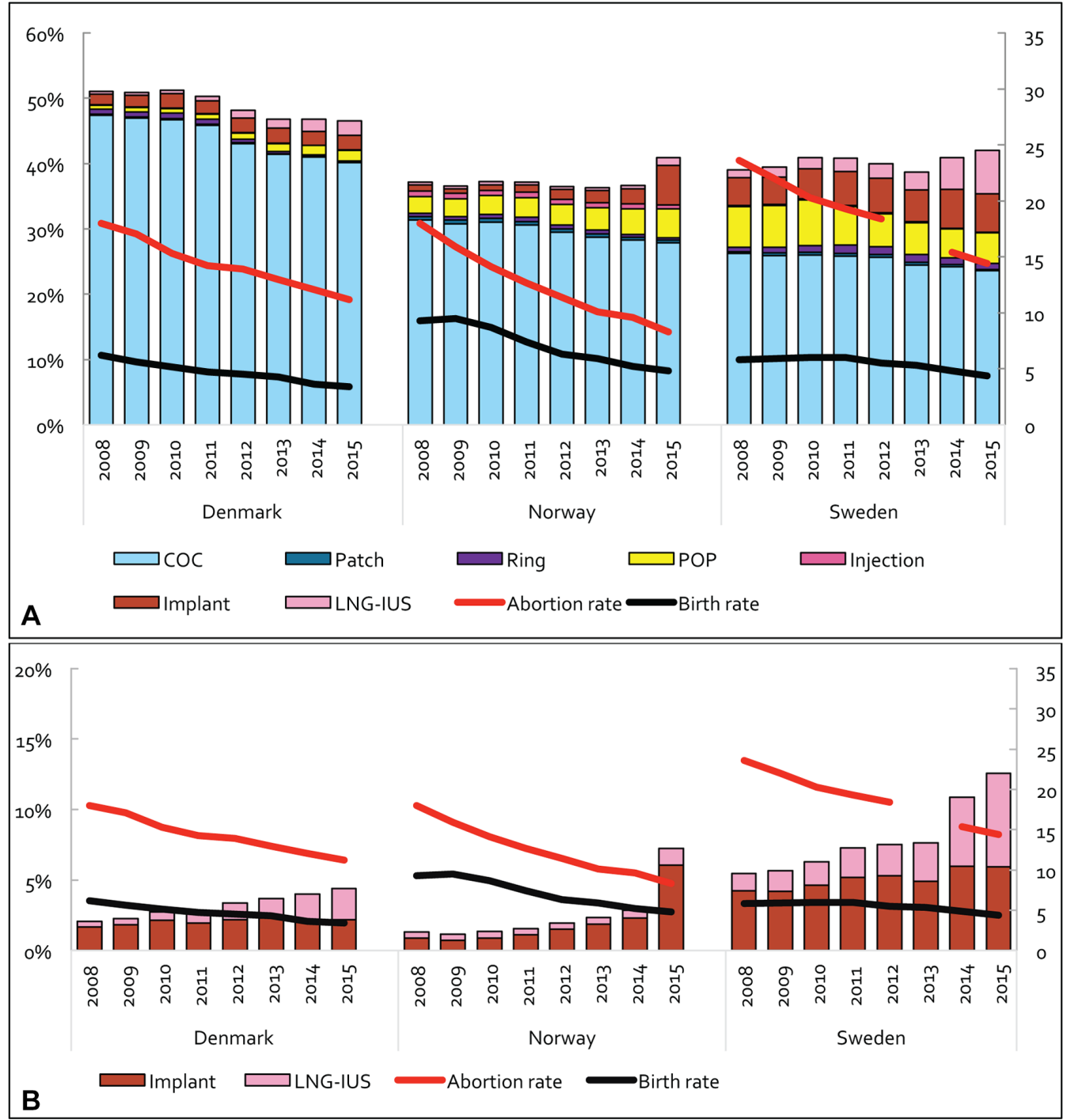

Figure 2 (A) Contraceptive use, birth and abortion rates among women aged 15-19 in Denmark, Norway and Sweden, 2008-2015. (B) Use of long-acting reversible contraceptives (LARC including implants and levonorgestrel-releasing intrauterine systems), birth and abortion rates among women aged 15-19 in Denmark, Norway and Sweden, 2008-2015. Y1 (left): use of hormonal contraception (\%). Y2 (right): birth and abortion rates (number of women/1000 women and year). Age-stratified abortion rates were not available for 2013 in Sweden. COC, combined oral contraceptives; Injection, depot medroxyprogesterone acetate (DMPA); LNG-IUS, levonorgestrel-releasing intrauterine system; POP, middle-dose or low-dose progestogen-only pill.

\section{Age-stratified births, abortions and use of hormonal} contraceptives in Denmark, Norway and Sweden, 2008-2015

The birth and abortion rates over the years 2008 through 2015 were very low among 13-14-year-old teenagers in all three countries. Births varied between 0 and 0.1 per 1000 teenagers a year in all three countries. Abortion rates varied between 1.7 and 0.5 in Denmark, 0.3 and 0.4 in Norway and 1.9 and 1.3 per 1000 teenagers in Sweden (during 2008-2012 in Sweden, no data available 20132015). The use of hormonal contraceptives was also very low in this age group (from $5 \%$ to $3 \%$ in Denmark, $1 \%$ in Norway and from $1 \%$ to $2 \%$ in Sweden) (figure $3 \mathrm{~A}$ and figure $4 \mathrm{~A})$.

Birth rates varied around 2 per 1000 teenagers yearly in all three countries among 15-17-year-olds. The abortion rates in the same age group declined from 12 to 6 in
Denmark, 8 to 4 in Norway and 17 to 12 per 1000 teenagers in Sweden (during 2008-2012 in Sweden, no data available 2013-2015). Denmark had a markedly higher use of hormonal contraceptives (from $40 \%$ to $34 \%$ ) than Norway (from 25\% to 27\%) and Sweden (from 29\% to $30 \%$ ) among 15-17-year-olds. Combined hormonal contraceptives (CHC) was the most commonly used method in all countries. Use of LARC, including implants and LNG-IUS, increased from $2 \%$ to $3 \%$ in Denmark, $1 \%$ to $6 \%$ in Norway and $4 \%$ to $9 \%$ in Sweden (figure $3 \mathrm{~B}$ and figure 4B).

A more marked decrease of the birth rate was seen among 18-19-year-olds in Norway (from 20 to 10 per 1000 teenagers) compared with the other two countries (from 13 to 7 in Denmark and from 12 to 9 in Sweden), where Norway started off on a higher level in 2008. The abortion 


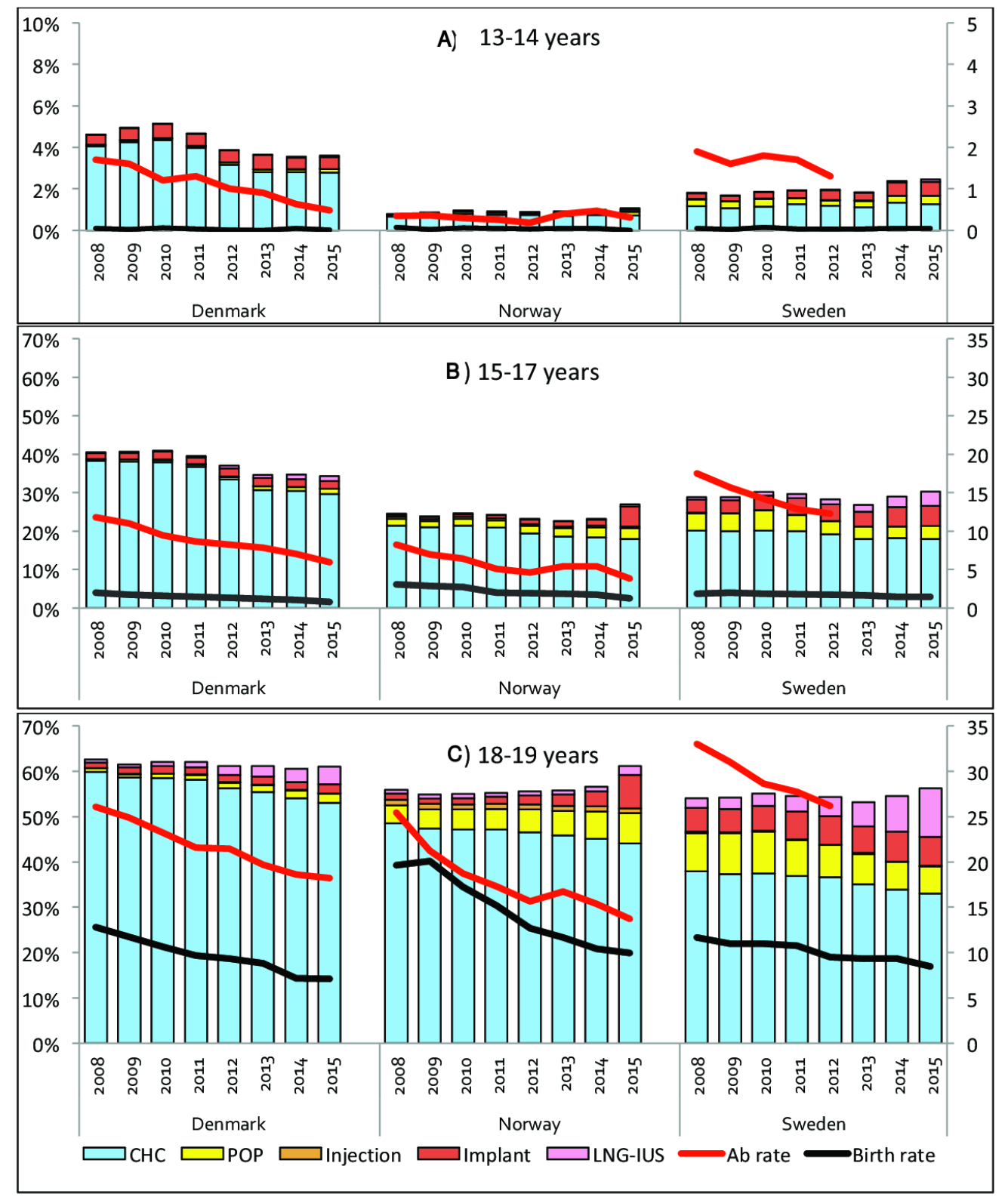

Figure 3 (A-C) Contraceptive use, birth and abortion rates among women aged 13-19 in Denmark, Norway and Sweden, 2008-2015, according to age groups. Please note the different scales. Y1 (left): use of hormonal contraception (\%). Y2 (right): birth and abortion rates (number of abortion or births/1000 women). Age-stratified abortion rates were not available for $2013-15$ in Sweden. Ab rate, abortion rate; CHC, combined hormonal contraceptives (subgroups oral, vaginal and transdermal); Injection, depot medroxyprogesterone acetate (DMPA); LNG-IUS, levonorgestrel-releasing intrauterine system; POP, middle-dose or lowdose progestogen-only pill.

rates in the same age group declined from 26 to 18 per 1000 in Denmark, from 25 to 14 in Norway and 33 to 26 per 1000 teenagers in Sweden (during 2008-2012 in Sweden, no data available 2013-2015). The overall user rates of hormonal contraceptives among teenagers 18-19 years of age varied between $63 \%$ and $61 \%$ in Denmark, $56 \%$ and $61 \%$ in Norway and $54 \%$ and $56 \%$ in Sweden. CHC were the most commonly used method in all countries. Use of LARC, including implants and LNG-IUS, increased from $2 \%$ to $6 \%$ in Denmark, $2 \%$ to $9 \%$ in Norway and $7 \%$ to $17 \%$ in Sweden (figure 3C and figure 4C).

\section{DISCUSSION}

Birth and abortion rates among teenagers in all the Nordic countries have declined between 2008 and 2015. During the same time period, more than half of the 18-19-year-old women were using hormonal contraception. The use of LARC increased, especially among 18-19-year-olds, while there was a small reduction in the use of $\mathrm{CHC}$ and POP. Birth and abortion rates were low in the Nordic countries compared with overall worldwide rates among teenagers. ${ }^{12}$ Moreover, the decreasing rate of teenage births has not been offset by an increasing abortion rate. 


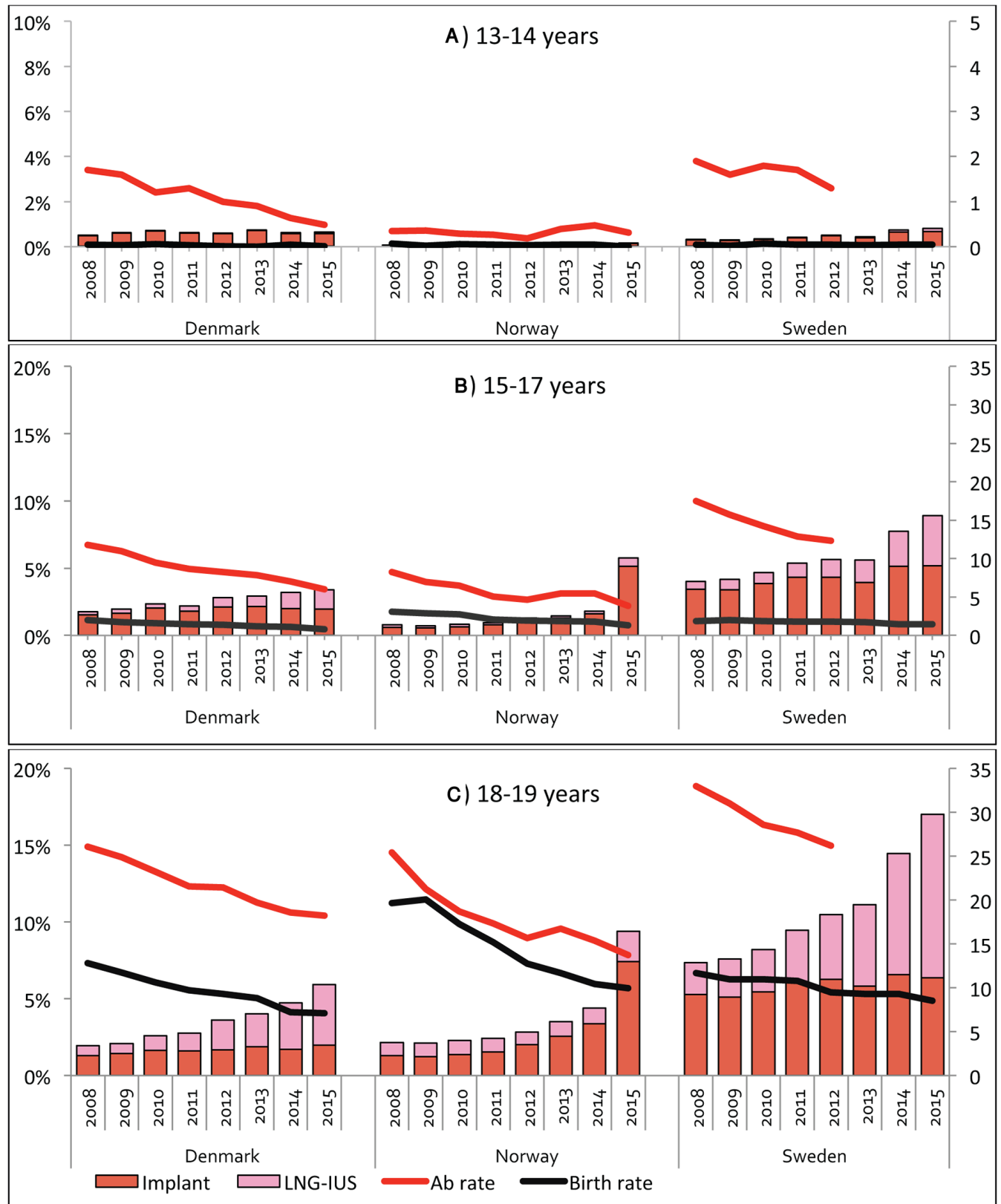

Figure 4 (A-C) Use of long-acting reversible contraceptives (LARC including implants and levonorgestrel-releasing intrauterine systems), birth and abortion rates among women aged 13-19 in Denmark, Norway and Sweden, 2008-2015, according to age groups. Please note the different scales. Y1 (left): use of LARC (\%). Y2 (right): birth and abortion rates (number of abortion or births/1000 women). Age-stratified abortion rates were not available for 2013-2015 in Sweden. Ab rate, abortion rate; LNGIUS, levonorgestrel-releasing intrauterine system.

The strength of this study was the use of national register data, which included all adolescents in the Nordic countries. All the registries are considered reliable. However, redeemed prescriptions do not necessarily mean that the contraceptives actually have been used. Nevertheless, when assessing contraceptive use, pharmacy claims have been shown to be more reliable than self-reported use, as women tend to overestimate their contraceptive use.$^{35}$ Online purchases of pharmaceutical drugs without a registered prescription are not included in the study. Since prescribed hormonal contraceptives are available and affordable to most adolescents in the
Nordic countries, the proportion of online purchases without a prescription is not considered to be significant. A limitation in this study was the lack of age-specific data on contraceptive use from Finland and Iceland.

Although declining, Sweden had the highest teenage abortion rate and the reasons for that are not obvious. The observed differences in overall user rates of hormonal contraceptives could not explain the differences in abortion rates since, for example, Norway had a lower user rate than Sweden, but still had lower abortion rates.

The risk of unplanned pregnancies is determined by three main factors: the proportion of sexually active 
women in the studied age group, the proportion of women using any contraceptive method and the efficacy of the contraceptive used.

Concerning sexual activity, a study including 65000 women in Denmark, Iceland, Norway and Sweden reported that the number of sexual partners and median age for first intercourse (16 years) was the same in all countries. ${ }^{36}$ However, the study only covers the years 2004-2005. The declining pregnancy rate seen in all the Nordic countries during the study period could be due to postponed time of first intercourse and/or declining sexual activity among teenagers, but there are no recent studies to support or reject this statement.

Regarding the second identified factor, proportion of contraceptive users, there were only small differences between the three Nordic countries studied and the proportion did not increase more in countries with the steepest decrease in births and abortion rates. The timing of initiation of contraceptive use might play a role though since it has been shown that initiation before or at first intercourse is associated with lower future abortion rates compared with initiation after the first intercourse. ${ }^{37}$ We were not able to estimate the proportion of women using other methods such as copper IUDs, condoms, fertility awareness methods and emergency contraceptives. According to national ${ }^{16} 1838$ and European studies, ${ }^{20} 39$ condoms are a frequently used contraceptive method among teenagers with pronounced user-dependent efficacy. There might be differences in condom use between the Nordic countries that can influence the pregnancy rates.

The third important factor is the quality of the contraceptive use. There is robust scientific evidence of the high efficacy of LARC methods. ${ }^{40}{ }^{41}$ During the last 10-15 years, the promotion of LARC as the most effective form of contraception has increased and it has been reflected in, for example, national guidelines on contraception. This recommendation also applies to teenagers. Norwegian, Swedish and, to a lesser extent, Danish teenagers have increased their use of LARC (including LNG-IUS and implants) at the expense of CHC and POP during the most recent years. There was a shift towards recommending LARC already in the guidelines for contraception in 2005 in Sweden, but in the updated guidelines from 2014, LARC was strongly recommended as a first option also for teenagers. Norway has made similar recent updates for recommendations of LARC. In 2014, also a smaller LNG-IUS (Jaydess) was introduced in the market as an IUS especially well suited for young women. It is likely that these actions are at least some of the reasons for the increasing use of LARC seen in this study, especially among 18-19-year-old women. During the same period of time, abortion rates in all the countries included in this study have reached their all-time low mark.

Sexual activity, contraceptive user rate and the quality of the contraceptive use can be influenced by a number of factors. Simultaneously, with the liberalisation of the abortion laws in the 1970s, the Nordic countries also focused on easy access to contraceptives, establishment of family planning services, youth clinics and sexuality education programmes. The implementation of these routines differed to some extent between countries. To ensure easy access to contraceptives, general practitioners in Denmark and Norway were given the main responsibility of prescribing contraceptives, although since 2006, public health nurses and midwives have also been granted authorisation to prescribe hormonal contraceptives. In Sweden, midwives have been the main prescriber since the 1970s. Unfortunately, they have, to a great extent, been left without medical advisors, which might influence their recommendations of contraceptives. For instance, the relatively high use of POP shown in this study in Sweden might be due to the fact that there are fewer contraindications for POP than CHC, and without the necessary medical support, it is safer to prescribe POP than $\mathrm{CHC}$ although POP has a lower continuation rate. ${ }^{42}$

It has been suggested that sexuality education programmes may lower teenage pregnancy rates by postponing the first sexual intercourse and by increasing both contraceptive user rates and quality of use. There is however a wide variety of programmes, and from the studies, it is difficult to draw conclusions about the extent to which programmes actually affect teenage pregnancy rates in practice. ${ }^{43}$ A Cochrane review of school-based sexuality education programmes found no evidence of an impact on pregnancy rates. There was however a low grade of evidence for an impact of incentives to stay in school on lower pregnancy rates. It should be noted that the majority of the studies included in the review were from low/middle-income countries. ${ }^{44}$ All the Nordic countries have compulsory sexuality education in schools but Finland has the most extensive programme of all the countries. Finland, with the current lowest abortion rate among the Nordic countries, witnessed an increase in the abortion rate in the mid-1990s just after the programme was no longer considered mandatory. After reinstituting a comprehensive compulsory sexuality education programme again in all Finnish schools in the early 2000s, the abortion rate dropped again. ${ }^{45}$ In Finland, the programme is part of the specific school subject 'Health science' taught only by qualified teachers, in contrast to the other Nordic countries where sexuality education can be integrated in any other school subject and has a less well-defined curriculum.

It has also been suggested that subsidies of contraceptives can lower pregnancy rates. However, Denmark, without any subsidies at all, has a higher contraceptive user rate and a lower abortion rate than Sweden, which offers subsidies for young women. This is in keeping with the findings from an English study where staying in school rather than the promotion of LARC seemed to have a higher impact on the teenage pregnancy rate. ${ }^{46}$ On the other hand, in the Contraceptive CHOICE Project where subsidies were combined with an extensive promotion of LARC in the St Louis area of the USA, the teenage pregnancy rate did decrease. ${ }^{47}$ Also, a recent study 
from Finland where LARC was provided free of charge in one large community, but not in another, reported an increased uptake of LARC methods and a declining rate of abortions among all teenagers in the community with free-of-charge LARC. ${ }^{48}$ In Sweden, there have been temporary and regional declines in abortion rates when local subsidies have been launched together with promotion campaigns for, for example, LARC, but the impact on the overall and long-term abortion rate has been difficult to detect.

In conclusion, we report steadily declining teenage birth and abortion rates, high user rate of hormonal contraceptives and an increasing use of LARC. A number of factors that could possibly influence contraceptive use and pregnancy rates have been discussed, such as easy access to youth clinics, promotion of LARC and sexuality education programmes. These factors would be of great interest to investigate further.

\section{Author affiliations}

${ }^{1}$ Department of Obstetrics and Gynecology, Sahlgrenska Academy at Gothenburg University, Sahlgrenska University Hospital, SE-41685 Gothenburg, Sweden ${ }^{2}$ Research Group Epidemiology of Chronic Diseases, Department of Community Medicine, Faculty of Health Sciences, UiT The Arctic University of Norway, Tromso, Norway

${ }^{3}$ Department of Women's and Children's Health, Division of Obstetrics and Gynaecology, Karolinska Institutet and Karolinska University Hospital, Stockholm, Sweden

${ }^{4}$ Department of Obstetrics and Gynaecology, University of Helsinki and Helsinki, University Hospital, Helsinki, Finland

${ }^{5}$ Department of Obstetrics \& Gynaecology, Rigshospitalet, Faculty of Health Sciences, University of Copenhagen, Copenhagen, Denmark

Acknowledgements We thank Ellen Lundqvist and Anastasios Pantelis (The National Board of Health and Welfare, Sweden), Mimir Arnorsson (Icelandic Medicines Agency), Hildur Björk Sigbjörnsdottir (Directorate of Health, Iceland), Prof Mika Gissler (National Institute for Health and Welfare, Finland) and Tinna Voipio (Finnish Medicines Agency) for providing data.

Contributors $\mathrm{HH}, \mathrm{FES}, \mathrm{OH}, \mathrm{KG}-\mathrm{D}, \mathrm{IM}, \mathrm{OL}$ and IL developed the study design. HH, IL, $\mathrm{FES}, \mathrm{OH}$ and $\mathrm{OL}$ collected the data. $\mathrm{HH}, \mathrm{FES}, \mathrm{OH}, \mathrm{KG}-\mathrm{D}, \mathrm{IM}, \mathrm{OL}$ and IL analysed the data. The first draft of the manuscript was prepared by HH and IL. FES, OH, KG-D, IM, OL contributed in a critical discussion regarding the final manuscript. HH, FES, $\mathrm{OH}, \mathrm{KG}-\mathrm{D}, \mathrm{IM}, \mathrm{OL}$ and IL had access to the data and approved of the final version of the manuscript submitted.

Funding This work was supported by a National LUA/ALF grant GBG3050 and grants from the Gothenburg Medical Society, Hjalmar Svensson's Fund and the University of Gothenburg. The researchers were independent of the funders.

Competing interests All authors have completed the Unified Competing Interest form at www.icmje.org/coi.disclosure.pdf (available on request from the corresponding author) and declare that IL has received compensation from Bayer AG, MSD and Actavis for lectures and participation in an Advisory Board during the previous 3 years; FES has over the past 3 years nothing to disclose; KGD has served ad hoc on advisory boards or as invited speaker for Bayer AG, Merck/MSD, Actavis, HRA-Pharma, Exelgyn, Mithra, NaturalCycles and Gedeon Richter; $\mathrm{OH}$ has served ad hoc on advisory boards or as invited speaker for Bayer AG, MSD, Actavis, Exelgyn, Sandoz and Gedeon Richter; HH has had no relationships with any company in the previous 3 years; IM has served ad hoc on advisory boards or as invited speaker for Bayer AG, Gedeon Richter and Actavis during the previous 3 years; $\emptyset \mathrm{L}$ has within the last 3 years received honoraria for presentation/lectures in pharmacoepidemiological issues. For all authors, their spouses, partners or children have no financial interests that may be relevant to the submitted work.

Patient consent Not required.

Provenance and peer review Not commissioned; externally peer reviewed.
Data sharing statement Aggregated data from national registries used in the study are available at reasonable request from the corresponding author. Consent for data sharing was not obtained, but the presented data are anonymous and there is no risk for identification of individual patients.

Open access This is an open access article distributed in accordance with the Creative Commons Attribution Non Commercial (CC BY-NC 4.0) license, which permits others to distribute, remix, adapt, build upon this work non-commercially, and license their derivative works on different terms, provided the original work is properly cited, appropriate credit is given, any changes made indicated, and the use is non-commercial. See: http://creativecommons.org/licenses/by-nc/4.0/.

\section{REFERENCES}

1. WHO. Adolescent pregnancy Fact sheet. 2014 http://www.who.int/ mediacentre/factsheets/fs364/en/.

2. Black AY, Fleming NA, Rome ES. Pregnancy in adolescents. Adolesc Med State Art Rev 2012;23:123-38.

3. Patel PH, Sen B. Teen motherhood and long-term health consequences. Matern Child Health J 2012;16:1063-71.

4. Kawakita T, Wilson K, Grantz KL, et al. Adverse Maternal and Neonatal Outcomes in Adolescent Pregnancy. J Pediatr Adolesc Gynecol 2016;29:130-6.

5. Leppälahti S, Gissler M, Mentula M, et al. Is teenage pregnancy an obstetric risk in a welfare society? A population-based study in Finland, from 2006 to 2011. BMJ Open 2013;3:e003225.

6. Leppälahti S, Heikinheimo $\mathrm{O}$, Kalliala I, et al. Is underage abortion associated with adverse outcomes in early adulthood? A longitudinal birth cohort study up to 25 years of age. Hum Reprod 2016;31:2142-9.

7. Paranjothy S, Broughton H, Adappa R, et al. Teenage pregnancy: who suffers? Arch Dis Child 2009;94:239-45.

8. McDaid LA, Collier J, Platt MJ. Previous Pregnancies Among Young Women Having an Abortion in England and Wales. $J$ Adolesc Health 2015;57:387-92.

9. Falk G, Ostlund I, Magnuson A, et al. Teenage mothers - a highrisk group for new unintended pregnancies. Contraception 2006;74:471-5.

10. Mentula MJ, Niinimäki M, Suhonen S, et al. Young age and termination of pregnancy during the second trimester are risk factors for repeat second-trimester abortion. Am J Obstet Gynecol 2010;203:107.e1-107.e7.

11. Lindberg L, Santelli J, Desai S. Understanding the decline in adolescent fertility in the United States, 2007-2012. J Adolesc Health 2016;59:577-83.

12. Sedgh G, Finer LB, Bankole A, et al. Adolescent pregnancy, birth, and abortion rates across countries: levels and recent trends. $J$ Adolesc Health 2015;56:223-30.

13. Central statistics office. Ireland. http://www.cso.ie/en/releasesandp ublications/ep/p-vsys/vitalstatisticsyearlysummary2016/

14. IFPA. Abortions in Ireland: statistics. https://www.ifpa.ie/Hot-Topics/ Abortion/Statistics

15. Vlietman M, Sarfraz AA, Eskild A. Induced abortion: a means of postponing childbirth? Changes in maternal age at induced abortion and child birth in Norway during 1979-2007. Acta Obstet Gynecol Scand 2010;89:1564-70.

16. Lindh I, Hognert $\mathrm{H}$, Milsom I. The changing pattern of contraceptive use and pregnancies in four generations of young women. Acta Obstet Gynecol Scand 2016;95:1264-72.

17. Bender S, Geirsson RT, Kosunen E. Trends in teenage fertility, abortion, and pregnancy rates in Iceland compared with other Nordic countries, 1976-99. Acta Obstet Gynecol Scand 2003;82:38-47.

18. Bratlie M, Aarvold T, Skårn ES, et al. Long-acting reversible contraception for adolescents and young adults - a cross-sectional study of women and general practitioners in Oslo, Norway. Eur J Contracept Reprod Health Care 2014;19:194-202.

19. Justad-Berg RT, Eskild A, Strøm-Roum EM. Characteristics of women with repeat termination of pregnancy: a study of all requests for pregnancy termination in Norway during 2007-2011. Acta Obstet Gynecol Scand 2015;94:1175-80.

20. Nic Gabhainn S, Baban A, Boyce W, et al. How well protected are sexually active 15-year olds? Cross-national patterns in condom and contraceptive pill use 2002-2006. Int J Public Health 2009;54 Suppl 2(Suppl 2):209-15.

21. Godeau E, Nic Gabhainn S, Vignes C, et al. Contraceptive use by 15-year-old students at their last sexual intercourse: results from 24 countries. Arch Pediatr Adolesc Med 2008;162:66-73.

22. Danish National Health Registries.

23. Tigrab database. http://www.tigrab.dk 
24. THL. The national institute for health and welfare (Finland). http:// www.thl.fi

25. The directorate of Health, Embaetti landlaeknis. https://www. landlaeknir.is/english/

26. Norwegian Institute of Public health. http://www.fhi.no

27. National Board of Health and Welfare. http://www.socialstyrelsen.se

28. WHO. Safe and unsafe induced abortion. Global and regional levels in 2008 and trends during 1995-2008. $2012 \mathrm{http}: / /$ apps.who.int/iris/ bitstream/10665/75174/1/WHO_RHR_12.02_eng.pdf

29. National Registry of Medicinal Product Statistics. http://www. medstat.dk

30. Norwegian Prescription Database. http://www.norpd.no

31. Cea Soriano L, Wallander MA, Andersson S, et al. The continuation rates of long-acting reversible contraceptives in uk general practice using data from the health improvement Network. Pharmacoepidemiol Drug Saf 2015;24:52-8.

32. Nelson A, Apter D, Hauck B, et al. Two low-dose levonorgestrel intrauterine contraceptive systems: a randomized controlled trial. Obstet Gynecol 2013;122:1205-13.

33. Øvre-Eide V, Skjeldestad FE. Use pattern for contraceptive implants in Norway. Acta Obstet Gynecol Scand 2016;95:1244-50.

34. Fakta om Norden/Figures and Statistics. 2015 http://www.norden. org/en/fakta-om-norden-1/figures-and-statistics

35. Triebwasser JE, Higgins S, Secura GM, et al. Pharmacy claims data versus patient self-report to measure contraceptive method continuation. Contraception 2015;92:26-30.

36. Jensen KE, Munk C, Sparen P, et al. Women's sexual behavior. Population-based study among 65,000 women from four Nordic countries before introduction of human papillomavirus vaccination. Acta Obstet Gynecol Scand 2011;90:459-67.

37. True $\mathrm{K}, \mathrm{Bajos} \mathrm{N}$, Bohet $\mathrm{A}$, et al. Timing of contraceptive initiation and association with future sexual and reproductive outcomes. Hum Reprod 2014;29:1651-8.
38. Lindh I, Blohm F, Andersson-Ellström A, et al. Contraceptive use and pregnancy outcome in three generations of Swedish female teenagers from the same urban population. Contraception 2009;80:163-9.

39. Avery L, Lazdane G. What do we know about sexual and reproductive health of adolescents in Europe? Eur J Contracept Reprod Health Care 2010;15 Suppl 2(Suppl 2):S54-S66.

40. Trussell J. Contraceptive failure in the United States. Contraception 2011;83:397-404.

41. Rose SB, Lawton BA. Impact of long-acting reversible contraception on return for repeat abortion. Am J Obstet Gynecol 2012;206:37. e1-37.e6.

42. Josefsson $A$, Wiréhn $A B$, Lindberg $M$, et al. Continuation rates of oral hormonal contraceptives in a cohort of first-time users: a population-based registry study, Sweden 2005-2010. BMJ Open 2013;3:e003401.

43. Goesling B, Colman S, Trenholm C, et al. Programs to reduce teen pregnancy, sexually transmitted infections, and associated sexual risk behaviors: a systematic review. J Adolesc Health 2014;54:499-507.

44. Mason-Jones AJ, Sinclair D, Mathews C, et al. School-based interventions for preventing HIV, sexually transmitted infections, and pregnancy in adolescents. Cochrane Database Syst Rev 2016;11:CD006417.

45. Falah-Hassani K, Kosunen E, Shiri R, et al. Adolescent sexual behavior during periods of increase and decrease in the abortion rate. Obstet Gynecol 2009;114:79-86.

46. Girma S, Paton D. Is education the best contraception: the case of teenage pregnancy in England? Soc Sci Med 2015;131:1-9.

47. Winner B, Peipert JF, Zhao Q, et al. Effectiveness of long-acting reversible contraception. N Engl J Med 2012;366:1998-2007.

48. Gyllenberg F, Juselius M, Gissler M, et al. Long-acting reversible contraception free of charge, method initiation, and abortion rates in Finland. Am J Public Health 2018;108:538-43. 